\title{
FREQUENCIA ALÉLICA E GENOTÍPICA DO GENE DGAT1EM UMA POPULAÇÃO DE BOVINOS DE LEITE
}

\author{
ALLELE AND GENOTYPE FREQUENCY OF DGAT1 GENE IN A CATTLE POPULATION \\ Silva, S.C.C. ${ }^{1 *}$, Vesco, A.P. ${ }^{1}$, Luizzeti, F. ${ }^{1}$, Gasparino, E. ${ }^{1}$, Bagatoli, A. ${ }^{1}$, Marques, L.A. ${ }^{1}$, \\ Voltolini, D.S.M. ${ }^{1}$, Oliveria, D.P. $\mathrm{de}^{1}$ e Souza, K.R.S. ${ }^{2}$
}

'Zootecnia. Universidade Estadual de Maringá. Maringá-Paraná. Brasil. *stefania_caroline@hotmail.com ${ }^{2}$ Genética e Melhoramento. Universidade Federal de Viçosa. Viçosa-Minas Gerais. Brasil.

\section{PalaVRas chaVe ADICIONAIS}

Diacilglicerol aciltransferase 1. Polimorfismo. Síntese de gordura.

\section{RESUMO}

O gene DGAT1 é um gene candidato envolvido com o conteúdo de gordura no leite. Neste estudo foram analisadas amostras de DNA de 72 bovinos leiteiros de uma população parcialmente fechada através amostras de sangue. O DNA foi extraído utilizando $C T A B$ e proteinase $\mathrm{K}$. A região alvo do gene foi amplificada por $\mathrm{PCR}$ e os resultados foram visualizados com a utilização de gel de poliacrilamida. Na população em estudo foi verificada a presença de quatro alelos, cujas frequências foram: $A=4,0 \%, B=50 \%, C=40 \%$, e $D=6,0 \%$. Foi verificado o equilíbrio de Hardy-Weinberg através do teste de $\chi^{2}$, concluindo-se que a população não se encontrava em equilíbrio para o locos avaliado.

\section{SUMMARY}

$D G A T 1$ gene is a candidate gene involved in fat content in milk and. This study analyzed DNA samples from 72 dairy cattle using blood samples. DNA was extracted use CTAB and proteinase $K$. The target region of the gene was amplified by PCR and the results were visualized with the use of polyacrylamide gel. The level of significance adopted was $5 \%$ for all analysis. Four alleles were checked their frequencies were: $A=4.0 \%, B=$ $50 \%, C=40 \%$, and $D=6.0 \%$. It was verified the Hardy-Weinberg using the Chi square test concluding that the population was not in balance.

\section{INTRODUÇÃO}

O uso de seleção fenotípica em longo prazo pode alterar a frequência alélica,

\section{Additional KeYWORdS}

Diacylglycerol acyltransferase 1. Polymorphism. Fat synthesis.

afetando um ou mais caracteres, resultando além da resposta direta no caractere selecionado, como também em respostas correlacionadas em muitos outros caracteres.

Muitos genes que apresentam polimorfismos conhecidos e com aplicações confirmadas já foram descritos e alguns patenteados, sendo que muitos genes polimórficos apresentam interesse econômico, dentre eles, o gene DGAT1 (diacilglicerol aciltransferase 1) (Grisard et al., 2004 e Winter et al., 2002).

O DGAT1 tornou-se um gene candidato funcional e posicional para o conteúdo de gordura no leite, baseado, respectivamente, no fenótipo de ausência de lactação observada em camundongos deficientes do gene (Riquet et al., 1999) e devido a sua posição próxima a um QTL de grande impacto na produção de leite (Spelman et al., 2002 e Bennewitz et al., 2004). Kuhn et al. (2004) relataram uma forte evidência para a separação de pelo menos três alelos na região promotora do gene $D G A T 1$ que afeta o percentual de gordura do leite. Em bovinos o $D G A T 1$ tem aproximadamente, $8,6 \mathrm{~Kb}$ e compreende 17 éxons, medindo em média 121,8 pb, e está localizado no cromossomo bovino 14 .

O gene $D G A T 1$ bovino codifica a enzima 
microssomal diacilglicerol aciltransferase (DGAT1) formada por 489 aminoácidos que utiliza acil-CoA diacilglicerol e substratos de gordura, catalisando a fase final da síntese de triglicérides, que ocorre na membrana do reticulo endoplasmático, afetando o metabolismo de gorduras, incluindo a produção de gordura e percentual do leite (Cases et al., 1998 e 2001).

Winter et al. (2002) encontrou dois polimorfismos na região promotora do gene (inicio da transcrição) sendo um deles um número variável de repetições em tanden (VNTR) na posição 1465. Em análises feitas com alguns rebanhos bovinos, foi encontrada uma sequência de 18 nucleotídeos (AGGCCCCGCCCTCCCCGG), localizadona região promotora do gene, ocasionando alteração de grande influência na concentração de gordura no leite (Thaller et al., 2003; Kuhn et al., 2004; Winter et al., 2004). Sousa et al., 2008 encontrou essa mesma sequência de 18 nucleotídeos em caprinos.

O objetivo do presente estudo foi levantar as frequências genotípicas e alélicas dos polimorfismos em VNTR na região promotora do gene DGAT1 em uma população de bovinos leiteiros fechada.

\section{MATERIALE MÉTODOS}

Foram avaliados os genótipos de 72 vacas de produção leiteira de um rebanho fechado. A população avaliada era composta por animais Holandês puros por origen $(44,44 \%)$, Holandês puro por cruzamento $(30,56 \%)$, animais sem registro de pedigree mistos Holandês/Pardo Suíço (1,39\%), Jersey $(1,39 \%)$ e Gir $(2,78 \%)$.

O material genético foi extraído de amostras de sangue coletadas da veia caudal dos animais, armazenadas em tubo contendo EDTA $(0,5 \mathrm{M})$, e mantidas sob refrigeração $\left(-20^{\circ} \mathrm{C}\right)$ até o momento da extração de DNA. A extração de DNA foi feita utilizando CTAB de acordo com o protcolo de Boyce et al. (1989).

Cada reação de PCR possuía um volume final de $10 \mu \mathrm{L}$, contendo as concentrações de 1,5 mM de $\mathrm{MgCl}_{2}, 0,2 \mathrm{mM}$ de dNTP, $5 \mu \mathrm{L}$ de cada primer (10 pmol), $0,2 \mathrm{U}$ de Taq DNA polimerase por reação e o DNA genômico. Foram utilizados os primers descritos por Kuhnetal.(2004),(DGAT1 F: 5'-TCAGGAT CCAGAGGTACCAG-3' e R: 5'-GGGGTC CAAGGTTGATACAG-3'). O programa de amplificação do material genômico com desnaturação a $94^{\circ} \mathrm{C}$ por $5 \mathrm{~min}, 35$ ciclos por $60 \mathrm{~s}$ a $94^{\circ} \mathrm{C}$, um ciclo com $20 \mathrm{~s}$ para o anelamento do primer a $60^{\circ} \mathrm{C}$, e um ciclo com $12 \mathrm{~s}$ de extensão a $72^{\circ} \mathrm{C}$. Ao fim desta etapa, foi realizada uma extensão final a $72^{\circ} \mathrm{C}$ por dois min.

As amostras foram visualizadas em gel de poliacrilamida $12 \%$ e corados com nitrato de prata em concentração de $12 \%$ e hidróxido de sódio a $18 \%$.

A genotipagem do polimorfismo de VNTR no promotor do gene DGAT1 foi conduzida de acordo com Kuhn et al. (2004), consistindo na amplificação e comparação com uma região entre as posições 1439 a 1565 da sequência do gene DGAT1 depositada no GenBank (AJ318490). Os fragmentos foram identificados e agrupados considerando-se alelo A - 110 pb, alelo B - 128 pb, alelo C - 146 pb, e alelo D - 164 pb, sendo que o alelo A apresenta 3 motivos repetidos, o alelo B, 4, o alelo C, 5 e o alelo D, 6 motivos repetidos. Foi realizada a determinação da frequência genotípica esperada e observada, frequência alélica, heterozigosidade observada e esperada, homozigosidade observada e esperada e o equilíbrio de Hardy-Weinberg através do teste de $\chi^{2}$, a um nível de significância de 5\%, utilizando o software POPGENE 1.31 (Yeh, 1999).

\section{RESULTADOSEDISCUSSÃO}

Para a genotipagem do polimorfismo DGAT1 VNTR, a metodologia utilizada mostrou-se adequada, com boa visualização dos genótipos.

Foram observados quatro alelos, com frequências iguais a $4,0 \%$ para o alelo A, 
$50 \%$ para o alelo B, $40 \%$ para o alelo C e $6,0 \%$ para o alelo D.

Com base na estimativa feita por meio de comparações com a sequência da região amplificada depositada no GenBank (AJ318490), estimou-se que o alelo A do DGAT1 VNTR apresenta 3 motivos repetidos, o alelo B, 4 motivos, o alelo C, 5 motivos e o alelo D, 6 motivos repetidos. Os alelos com dois ( $92 \mathrm{pb}$ ) e 7 motivos repetidos (182 $\mathrm{pb)}$ não foram encontrado neste trabalho. De modo geral, parece que os alelos B, C e $\mathrm{D}$ são mais frequentes. A frequência alélica encontrada na população de bovinos estudada apresentou semelhança com os valores encontrados na literatura, comprovando a existência de diferentes alelos para o mesmo gene.

Lacorte (2006) em uma amostra de 278 animais (228 animais Bos indicus das raças Gir, Guzerá, Nelore e Sindi, e 50 animais Bos taurus, da raça Holandesa) encontrou polimorfismos variando de duas a sete repetições nucleotídicas no total, dependendo da raça, sendo que os alelos mais frequentes encontrados foram os alelos três, quatro e cinco, que correspondem aos alelos $\mathrm{B}, \mathrm{C}$ e D encontrados neste trabalho.

O alelo com sete repetições também foi encontrado por Sanders et al. (2006) e Kuhn et al. (2004) apresentado efeito significativo para algumas características de produção de leite, como queda nos teores de lactose e aumento de contagem de células somática, quando comparado com os outros alelos encontrados.

Lacorte (2006) estudando o mesmo DGAT1 VNTR descreveu o alelo um com dois motivos repetidos. Em seu estudo este alelo foi descrito para as raças Nelore e Guzerá (Bos indicus), porém não foi encontrado na população Bos taurus por ele estudada. Esse alelo não foi encontrado neste estudo provavelmente por se tratar de uma população de Bos taurus. Em comparação com alguns trabalhos, o numero de alelos encontrado foi menor, talvez devido ao sistema de acasalamento utilizado na população estudada, onde apenas esporadicamente novos reprodutores eram introduzidos. Esse tipo de população cuja base genética é estreita poderia justificar a ocorrência de apenas 4 alelos, além de poder ter a taxa de endogamia aumentada e consequentemente perda de variabilidade genética.

Foram observados oito genótipos diferentes, sendo que as maiores frequências encontradas correspondem aos genótipos $\mathrm{BB}, \mathrm{CC}$ e $\mathrm{CD}$, fato este que reflete a predominância dos alelos B, C e D (tabela I).

$O$ valor encontrado no teste do $\chi^{2}$ foi $87,24(\mathrm{p}<0,05)$ indicando que as freqüências observadas diferem significativamente das esperadas, e que o loco DGAT1 não está em equilíbrio de Hardy-Weinberg na amostra estudada, provavelmente devido a estrutura genética da população, por se tratar de um rebanho com manejo de reposição dos animais oriundo do próprio plantel, sendo esporadicamente introduzido um reprodutor de for do rebanho. Nestas condições é natural que o equilíbrio não seja verificado, uma vez que o equilíbrio é mantido, quando a população é grande e os acasalamentos ocorrem ao acaso.

Tabela I. Frequência genotípica esperada (FGE) e observada (FGO) do gene DGAT1 na população de bovinos leiteiros. (Expected and observed genotype frequencies the DGAT1 gene in dairy cattle population).

\begin{tabular}{|c|c|c|c|}
\hline Genótipos & Observações & FGE & FGO (\%) \\
\hline$(A, A)$ & 2 & 0,11 & 2,8 \\
\hline$(B, A)$ & 2 & 3,02 & 2,8 \\
\hline$(B, B)$ & 32 & 17,87 & 44,4 \\
\hline$(\mathrm{C}, \mathrm{A})$ & 0 & 2,39 & 0,0 \\
\hline$(C, B)$ & 5 & 28,70 & 6,9 \\
\hline$(\mathrm{C}, \mathrm{C})$ & 23 & 11,16 & 31,9 \\
\hline$(D, A)$ & 0 & 0,38 & 0,0 \\
\hline$(\mathrm{D}, \mathrm{B})$ & 1 & 4,53 & 1,4 \\
\hline$(D, C)$ & 6 & 3,59 & 8,3 \\
\hline$(D, D)$ & 1 & 0,25 & 1,4 \\
\hline
\end{tabular}




\section{SILVAETAL.}

\section{BIBLIOGRAFIA}

Bennewitz, J., Reinsch, N., Paul, S., Looft, C., Kaupe, B., Weimann, C., Erhardt, G., Thaller, G. Kühn, C., Schwerin, M., Thomsen, H., Reinhardt, F., Reents, R. and Kalm, E. 2004. The DGAT1 $\mathrm{K} 232 \mathrm{~A}$ mutation is not solely responsible for the milk production quantitative trait locus on the bovine chromosome 14. Am. Dairy Sci. Assoc., 87: 431-442.

Boyce, T.M., Zwick, M.E. and Aquadro, C.F. 1989. Mitochondrial DNA in bark weevils: size, structure, and heteroplasmy. Genetics, 123: 825-836.

Cases, S., Smith, S.J., Zheng, Y.W., Myers, H.M., Lear, S.R., Sande, E., Novak, S., Collins, C., Welch, C.B., Lusis, A.J., Erikson, S.K. and Farese, R.V. 1998. Identification of a gene encoding an acyl CoA: diacylglycerol acyltransferase, a key enzyme in triacylglycerol synthesis. Cell Biol., 95: 13018-13023.

Cases, S., Stone, S.J., Zhou, P., Yen, E., Tow, B., Lardizabal, K.D., Voelker, T. and Farese, R.V. Jr. 2001. Cloning of DGAT2, a second mammalian diacylglycerol acyltransferase, and related family members. J. Biol. Chem., 276: 3887038876.

Grisart, B., Farnir, F., Karim, L., Cambisano, N., Kim, J., Kvasz, A., Mni, M., Somon, P., Frère, J.M., Coppieters, W. and Georges, M. 2004. Genetics and functional confirmation of the causality of the DGAT1 quantitative trait nucleotide in affecting milk yield and composition. P. Natl. Acad. Sci., 101: 2398-2403.

Kuhn, C., Thaller, G., Winter, A., Kaupe, O.R.P.B., Erhardt, G., Bennewitz, J., Schwerin, M. and Fries, R. 2004. Evidence for multiple alleles at the DGAT1 locus better explains a quantitative trait locus with major effect on milk fat content in cattle. Genetics, 167: 1873-1881.

Lacorte, G.A. 2006. Caracterização dos polimorfismos DGAT1 K232 e DGAT1 VNTRem raças bovinas. Dissertação (Mestrado em Genética). Universidade Federal de Minas Gerais. MG. Belo Horizonte. 50 pp.

Riquet, J., Coppieters, W., Cambisano, N., Arranz,
J.J., Berzi, P., Davis, S.K., Grisart, B., Farnir, F., Karim, L., Mni, M., Simon, P., Taylor, J.F., Vanmanshoven, P., Wagenaar, D., Womack, J.E. and Georges, M. 1999. Fine-mapping of quantitative trait loci by identity by descent in outbred populations: Application to milk production in dairy cattle. P. Natl. Acad. Sci., 96: 9252-9257.

Sanders, K., Bennewitz, J., Reinsch, N., Thaller, G., Prinzenberg, E.M., Kühn, C. and Kalm, E. 2006. Characterization of the DGAT1 mutations and the CSN1S1 promoter in the German Angeln dairy cattle population. J. Dairy Sci., 89: 31643174.

Spelman, R.J., Ford, C.A., McElhinney, P., Gregory, G.C. and Snell, R.G. 2002. Characterization of the DGAT1 gene in the New Zealand dairy population. J. Dairy Sci., 85: 3514-3517.

Sousa, A.C., Soares, M.A.S., Rodrigues, S.M.T., Rodrigues, L.P.G.A., Namba, V. e Souza, R.B. 2008. Análises preliminares da região promotora do gene DGAT1 em caprinos leiteiros. Rev. Bras. Biociências, 6: 55-56.

Thaller, G., Krämer, W., Winter, A., Kaupe, B., Erhardt, G. e Fries, R. 2003. Effects of DGAT1 variants on milk production traits in German cattle breeds. J. Anim. Sci., 81: 1911-1918.

Winter, A., Kramer, W., Werner, F.A., Kollers, S., Kata, S., Durstewitz, G., Buitkamp, J., Womack, J.E., Thaller, G. and Fries, R. 2002. Association of a lysine-232/alanine polymorphism in a bovine gene encoding acyl-CoA:diacylglycerol acyltransferase (DGAT1) with variation at a quantitative trait locus for milk fat content. GenBank: AJ318490.1. <http://www.ncbi.nlm. nih.gov/nuccore/21425304? report=genbank> $(18 / 07 / 09)$

Winter, A., Alzinger, A. and Fies, R. 2004 Assessmente of the gene content of the chromosomal regions flanking bovine DGAT1. Genomics, 83: 172-180.

Yeh, F.C. 1999. POPGENE version 1.31. <http:// www.ualberta.ca/ fyeh> (10/05/09).

Archivos de zootecnia vol. 60, núm. 232, p. 1346. 